\title{
Originality and plagiarism: a question of authorship in the Academy
}

\author{
Rosemary Sadami Arai Shinkai ${ }^{1}$
}

Knowing that the expectation of the reader would be more than that of the text, I chose a broad title for this editorial. But my objective here is to initiate a reflection of disquiet, rather than to defend a finished thesis on the triad originality - authorship - plagiarism. This is simply because we have no universal definitions or concepts, unanimously accepted in this time and space, with all the biases of the various areas of knowledge and cultures. Thus, the difficulty in initiating by its essence compels us to reverse the natural order and analyze the deviation of virtue by the failure; namely, plagiarism as a tangible academic and scientific problem.

Although there is also no single definition for plagiarism, by necessity I adopt here the broad concept of the Brazilian Academy of Sciences, in its document on integrity in research: Plagiarism involves the appropriation of ideas and the work of others without proper credit and also,Self-plagiarism or republication of already released scientific results, as if they were new, without informing about the prior publication ${ }^{(1)}$.

Plagiarism detected in academic works and scientific publications implies a moral and legal violation of copyright and intellectual property, with possible academic and financial sanctions. In the context of the university, in the extreme case, the plagiarist can fail a course and lose rank or title. Although the legal view in relationship to plagiarism is not specific, there is a focus on copyright protection, which includes a citation in the Brazilian Penal Code, punishable by imprisonment or a fine for infringement of copyright ${ }^{(2)}$. Regarding scientific publications, established plagiarism can lead to retraction or correction of a published article. One recent research study showed that plagiarism corresponded to the cause of $9.8 \%$ of retracted articles in the PubMed database; as well, duplicate publication (self-plagiarism or redundancy) was cited in $14.2 \%$ of the cases ${ }^{(3)}$. Therefore, when detected, confirmed and judged, a case of plagiarism can be corrected to restore the actual authorship. But a major challenge is how to detect, confirm and judge plagiarism. In cases of scholarly journals, the Committee on Publication Ethics (COPE) ${ }^{(4)}$ offers assistance to editorial teams and makes available several support materials in an online format with open access.

In the majority of cases, the identification of plagiarism in a work occurs by chance or due to a complaint by a third party. Although information technology has provided software that detects duplication in the text and quantification in percentage, the question remains: how much similarity is sufficient to constitute plagiarism? And if the amount of text copied was small, but it used cardinal parts, such as the results or discussion? Or even, what if the text and the numbers are not identical, but the idea is? How does one identify, measure and judge something so subjective in an objective manner, and particularly at the same time? And who judges? And what happens next?

An article published in $2009^{(5)}$ showed there were still intercultural differences in the perception of plagiarism of ideas, data and text between Anglo-Saxon and Latin American researchers. Several other factors facilitating the practice of plagiarism were also analyzed by the authors, such as: the academic and scientific culture of productivity, ignorance of the limits of the appropriation of another's idea and work, deficiency of training in research integrity, lack of mastery of academic writing, of paraphrasing, and also of the English language ${ }^{(5)}$. If these are the possible causes of the problem, one can outline a strategy for the prevention and treatment of the illness.

The prevention of misconduct has its basis in general information, in faculty and editorial capacity building, in student education, and ongoing academic monitoring. Currently, our communities connected to teaching and research are still unprepared to avoid cases of plagiarism, whether intentional or not, derived in bad faith or by inexperience and ignorance of rules of responsible conduct in research. In the universities, there is need for clear institutional policies with delimitation of actors and roles to watch over the academic activities of students and faculty. However, the coordinated efforts to combat plagiarism and other forms of academic-scientific misconduct must be multi-sectorial, involving the government, associations related to teaching and research, funding agencies, publishers and the general public. Achieving this is no easy task, especially considering the promotion of best practices on a global scale, in a world that seeks the increasing sharing of information and knowledge through international institutions.

The Conferências Mundiais de Integridade em Pesquisa (World Conference on Research Integrity) stands out among global initiatives focusing on a broad discussion of international guidelines on the promotion of good academic-scientific practices and the combatting of misconduct. The fourth edition of the World Conference will take place in Rio de Janeiro in 2015(6), after previous events in Lisbon, Singapore and Montreal. It will be a unique opportunity for inserting the Brazilian scientific community increasingly into international cooperative efforts for responsible conduct in research and scientific publication. We, in Brazil, must do our part and put discourse into action. Plagiarism and other deviations will only be combated with the deliberate adherence and massive support of all who work for the qualification of education and for reliable and relevant science for society.

${ }^{1} \mathrm{PhD}$ in Clinical Dentistry. Professor at the Pontifícia Universidade Católica do Rio Grande do Sul (Pontifical Catholic University of Rio Grande do Sul), Porto Alegre, RS, Brazil. Editor in Chief of the Journal of Dental Science. Council member of the Committee on Publication Ethics - COPE, UK. rshinkai@pucrs.br 


\section{References}

1. Academia Brasileira de Ciências. Rigor e integridade na condução da pesquisa científica: guia de recomendações de práticas responsáveis [Internet]. Rio de Janeiro; 2013 [citado 2014 abr. 15]. Disponível em: http:// www.abc.org.br/IMG/pdf/doc-4311.pdf

2. Pithan LH, Oliveira AP. Ética e integridade na pesquisa: o plágio nas publicações científicas. Rev AMRIGS. $2013 ; 57(3): 240-5$

3. Fang FC, Steen RG, Casadevall A. Misconduct accounts for the majority of retracted scientific publications. Proc Natl Acad Sci U S A. 2012;109(42):17028-33.

4. Committee on Publication Ethics (COPE). Promoting integrity in research publication [Internet]. [cited 2014 Apr 15]. Available from: http://publicationethics.org/

5. Vasconcelos SMR, Leta J, Costa LOO, Pinto AL, Sorenson MM. Discussing plagiarism in Latin American science: Brazilian researchers begin to address an ethical issue. EMBO Rep [Internet]. 2009 [cited 2014 Apr 15];10(7):677-82. Available from: http://www.ncbi.nlm.nih.gov/pmc/articles/PMC2727439/

6. 4th World Conference on Research Integrity. Research Rewards and Integrity: Improving Systems to Promote Responsible Research, Rio de Janeiro; 2015 May 31-June 3 [Internet]. [cited 2014 Apr 17]. Available from: www.wcri2015.org 